\title{
Bridging Sustainability and Food Security Ideas Towards Building Sustainable Food Systems
}

\author{
Majing Oloko (Corresponding author) \\ School of Environment and Sustainability, University of Saskatchewan \\ 117 Science Place, Saskatoon, SK S7N 5C8, Canada \\ E-mail: mjshimang@yahoo.ca
}

Received: January 1, 2020 Accepted: January 25, 2020 Published: January 27, 2020

doi:10.5296/ijgs.v4i1.16342 URL: https://doi.org/10.5296/ijgs.v4i1.16342

\begin{abstract}
Having stable access to nutritious and culturally preferred food to maintain health and well-being is still a challenge for many people across the globe. Food insecurity and environmental degradation is rising across the world with interrelated drivers. There has been increasing advocacy for the creation of sustainable food systems to support food and nutritional security without degrading the environment. Bridging sustainability and food security ideas is a step towards building such food systems. However, how to apply ideas of sustainability and food security into building sustainable food systems remains a challenge, given the connection between the two concepts is not well appreciated. I introduce a sustainability and food security assessment framework as a first step for bridging sustainability and food security concepts, towards building sustainable food systems.
\end{abstract}

Keywords: Food security, Food insecurity, Sustainability, Sustainable food systems

\section{Introduction}

Having stable access to nutritious and culturally preferred food to maintain health and well-is still a challenge for many people across the globe. The 2019 State of Food Security and Nutrition in the World (SOFI) shows that the number of people suffering food insecurity globally continues to rise for a third consecutive year (FAO, IFAD, UNICEF, WFP, \& WHO, 2019). Food insecurity is the lack of stable access to safe, nutritious and culturally acceptable food to lead a healthy life. Alongside growing food insecurity is also the rise in environmental degradation - the depletion of the earth's natural resources (UNEP, 2016; Whitmee et al., 2015). Factors that cause food insecurity and environmental degradation are interrelated. Reports highlight multiple drivers of the current food insecurity and 
environmental degradation trends; including, rising consumerism, increased consumption of low-nutrition food, climate change, loss of biodiversity, economic decline, conflict and bad governance (UNEP, 2016; FAO, IFAD, UNICEF, WFP, \& WHO, 2019). Food production through the modern industrialized food system is also contributing to environmental degradation and when the earth's natural resources deplete, food security prospects is affected (Inter Academy Partnership [IAP], 2018; Roe, 2019; Swaminathan \& Jana, 1992; Tscharntkea et al., 2011; Lal et al., 2004). The SOFI also highlights the complexity of tackling food insecurity due to the interlinkages of drivers and reiterates the need to rethink solutions in line with the sustainable development goals [SDG] (FAO, IFAD, UNICEF, WFP, \& WHO, 2019). This is an important move to once again connect the concepts of food security and sustainability - something that is not well acknowledged in sustainability or food security discourse (Berry, Dernini, Burlingame, Meybeck, \& Conforti, 2014).

There has been a steady surge in the advocacy for sustainable development in the last three decades. Sustainable development - "development that meets the needs of the present without compromising the ability of future generations to meet their own needs" (World Commission on Environment and Development [WCED], 1987: 43) - addresses environmental, economic and social needs. Among these needs is the need for food; a physiological need that must be reasonably met before moving to other needs; failure to do so results in deprivation and significantly impedes the achievement of other needs like health, resource development, employment and self-esteem (Huitt, 2007). This suggests that achieving stable food security for all is a pre-condition for the development of other areas of life in a sustainable way.

Manifest in the rise in diet-related diseases across the world, food insecurity is proving to be a costly problem. For example, in USA the cost of treating diet related diseases is estimated to rise from \$US 325 billion per year in 2014 to \$US 555billion in 2025 (WOF, 2017, in Huffpost 2017). Similarly, In Canada, the cost is estimated to reach \$US 207 billion per year in 2025 from about \$US 27.5 billion (WOF, 2017, in Abedi, M, 2017) - this is not sustainable. Food insecurity causes multiple health problem that affects the growth, development and wellbeing of children and adults, which in turn affects learning, skills acquisition, labour and community development. If this trend goes unchecked and the quality of human resources decline due to food insecurity-related challenges, the prospects of building sustainable communities in the future will be at risk. Considering these challenges, there have been calls for the building of sustainable food systems that address both food insecurity and associated environmental degradation issues (IAP, 2018).

This paper argues that there is a need for food security and sustainability to be treated as interrelated issues. I introduce a sustainability and food security assessment framework (SFSA) as a first step towards bridging ideas of sustainability and food security for building sustainable food systems at the community level. 
2. Establishing the Relationship Between the Concepts of Sustainability and Food Security

\subsection{Sustainability Dimensions}

The concept of sustainability has cut across various aspects of society and academic disciplines and has been used and defined in various ways (Palmer, 2003). Sustainability has been described as an ethical principle (Riedel, 2015), as a "traveling concept whose meaning changes" (Knauf, 2014: 2), and as a concept that has defied operationalization (Wiersum, 1995). The term 'sustainability' and 'sustainable development' are often used interchangeably. Over the years, sustainability has become widely represented and recognized through its three dimensions - environmental, social and economic dimensions (Purvis, Mao \& Robinson, 2018).

Environmental dimension of sustainability can be explained in terms of the balance between the harvest rates of earth's natural resources and its regeneration rate, and the balance between the natural assimilative capacities of the environment and waste emitted (Daly, 1999). Since the 1970's the earth's natural resources have been harvested beyond its regeneration rate, this is causing food shortages, climate change and loss of biodiversity (Global Footprint Network [GFN], 2019). Similarly, enormous amount of wastes (which mostly cannot be absorbed by the environment) make its way into food environments and threaten biodiversity in such ecosystems (Global Footprint Network [GFN], 2019; Kidd, et al., 2007).

The social dimension of sustainability deals with issues around meeting basic human needs, social equity, human behaviours and its impact on the biophysical environment, and sustainability decisions (Vallace, Perkins, \& Dickson, 2011). Food is a basic social need that social sustainability addresses, and food systems are part of bigger socio-ecological systems. Social factors such as culture, age, gender, governance and family can affect food security as much as ecological factors can (Bacon, Getz, Kraus, Montenegro, \& Holland, 2012). Social equity in the food security context ensures everyone has access to food regardless of their social status. Similarly, a people's culture and norms may determine how they interact with their immediate environment - including attitudes towards environmental conservation. For example, Indigenous people across the world have various connections with the environment for food, cultural and spiritual needs. Thus, they feel a sense of responsibility to respect and care for the environment (Sobreliva, 2008). Furthermore, leadership can impact on delivery of social equity - including the management and distribution of ecological services. There is a correlation between social inequality and environmental degradation (United Nations Research Institute for Social Development [UNRISD], 2019). People are better positioned to make more environmentally friendly decisions when there is social security - including access to affordable sustainable energy sources, access to education and research and subsidies.

Economic dimension of sustainability deals with balancing human needs and environmental needs, and the sustainability of economic systems. Robinson (2004) opined that the relationship between poverty and environmental concerns is one of the primary messages of 
the Brundtland report. The failure of world economic systems currently manifest in the harm done to the environment in the pursuit for 'development', and in widening poverty gaps across the globe (Ahmed, 2010; Osami, 1993). Poverty increases vulnerability to food insecurity by reducing people's access to food.

\subsection{Food Security Dimensions}

Food security "exists when all people, at all times, have physical, social and economic access to sufficient safe and nutritious food that meets their dietary needs and food preferences for an active and healthy life" (FAO, 2003:29). The concept of food security is identified by four dimensions: availability of food, access to food, food utilization, and stability of all the three dimensions (FAO, 1996). The availability dimension of food security entails physical availability of food through various means of food production and procurement. The access dimension of food security covers physical and economic access to food mostly at the household level. Food utilization dimension is concerned with the way the body uses food for optimal benefit of nutrients to maintain health and well-being. For food security to be maintained, food needs to be available, accessed and utilized at a sustainable rate. This speaks to the importance of ensuring that social, environmental and economic factors are favourable to safeguard food security.

\subsection{Tracing the Interconnectedness Between the Concepts of Sustainability and Food Security}

Before the concepts of food security and sustainability became introduced in the 1970's and 1980's respectively, many cultures around the world had it enshrined in their practices and customs. An example can be seen in how practice of reciprocity and respect for the environment is embedded in many Indigenous cultures' teachings (Kuhnlein et al., 2006). For such cultures, sustainability can manifest in the relationship they have with the food system; they may include farming practices or selective harvesting to support regeneration of biodiversity (Kanene, 2016; Bharucha \& Pretty, 2010); food waste reduction strategies that encourages harvesting only what is needed and using all that is taken (Martens, Cidro, Hart, \& McLachlan, 2016), and stewardship of natural resources (Rankoana, 2016; Power, 2008; Castleden, 2007). Food security, which is one of the primary outcomes of the relationship between people and food systems, fall under the sustainability umbrella -but the connection was not always acknowledged.

In first half of the $20^{\text {th }}$ century, the world got its first glimpses of a vulnerable global food system from reports by the then League of Nations and newly formed FAO respectively. Together, the reports presented a discouraging global food situation - food shortages in poorer nations, malnutrition, and a projection of more food shortages in the future (Simon, 2012). At first, it was understood that simply increasing food production, regulating food prices and re-distributing food (from surplus to deficit regions) would guarantee a world without hunger. After periods of surplus, powered largely by the so-called 'Green Revolution (Note 1)'; hunger was still a problem. Against major perceptions, this was an indication that the food problem faced at the time was not only because of low food production. Coined in 1974 amid a world food crisis, the term 'Food Security' acknowledged that there was a need for a global action; but it did not immediately capture the dimensions of the problem (as 


\section{Macrothink}

evident in its changing definition as shown in Table 1). Unfortunately, extreme climatic conditions, bad governance, poverty and denied social access would go ahead to cause subsequent famines in various regions in the 1980's and early 1990's (Simon, 2012).

The WCED 1987 report was perhaps one of the first indications of an evolving understanding of the causes and approaches to solving food insecurity. Addressing food security as a major issue in the report (Our Common Future-Chapter 5: Food Security: Sustaining the Potential) shows that food security was viewed as a sustainable development problem. This move announced a connection between food security and sustainability- something that has mostly been ignored prior to that. However, not much research and policies advanced this connection between food security and sustainability. This is evident in how food and nutritional security is growing under a dominant global industrialized food system that is contributing to various forms of environmental, economic, and social sustainability problems (IAP, 2018).

In recent times, the connection between sustainability and food security is again being re-established through the idea of a sustainable food system. A sustainable food system is a "food system that delivers food and nutrition security for all in such a way that the economic, social and environmental bases to generate food security and nutrition for future generations are not compromised" (High Level Task Force for Global Food and Nutrition Securities, 2015:1). However, how to translate this idea into practise and bring positive changes to the most vulnerable, remains a challenge. Sustainability and food security solutions are not straight forward; there are multiple environmental, economic and social factors to consider. I offer suggestions for bridging food security and sustainability ideas into projects mostly at the community level. I then offer an assessment framework as a first step or pre-condition for building sustainable food systems that bridge sustainability and food security ideas.

Table 1. Changing definitions of food security

\section{Definition}

Focus

References

"Availability at all times of adequate world

Food supply, price stability

FAO, 2006:1

food supplies of basic foodstuffs to sustain a steady expansion of food consumption and to offset fluctuations in production and prices" (World Food Conference, 1974)

"Ensuring that all people at all times have both physical and economic access to the basic food that they need" (FAO, 1983).
Food access: focus shifted to 'access' and the recognition that supply may not be the only problem
Napoli, 2011; FAO, 2006:1

"Access of all people at

Temporal dimension of food Napoli, all times to enough food for an active, 
chronic

and 2006

transitory food security and

their causes

"Food security exists when all people, at all times, have physical and economic access to sufficient, safe and nutritious food that meets their dietary needs and food preferences for an active and healthy life" (World Food Summit, 1996)

Food security "exists when all people, at all times, have physical, social and economic access to sufficient safe and nutritious food that meets their dietary needs and food preferences for an active and healthy life" (FAO, 2003:29)
A shift to recognize the four dimensions of food security: utilization (nutritional quality), access, stability and availability
Adding 'social' access to FAO, 2003 food recognizes the problem of access by vulnerable people.
FAO, 2006:1; Napoli, 2011

Please note that there are hundreds of definitions of food security, thus this table is by no means exhaustive. However, it provides 'milestone' definitions by globally recognized world bodies that focus on food security affairs.

\section{Bridging Sustainability and Food Security Ideas}

One of the areas where sustainability and food security ideas can be bridged is through transdisciplinary research; where scholars, practitioners and community can partner on projects. For example, projects can be planned, executed and evaluated by a team of sustainability scientists, non-academic and academic food systems experts, non-governmental organizations that support local food security programs and the SDG, and local communities. One of the benefits of collaboration is the unique strengths that each partner brings to complement the others. Although collaboration alone does not guarantee that positive results will emerge, but with collaboration, projects are more likely to focus on sustainability and food security issues that are of importance to communities.

One of the factors that may exacerbate food insecurity is the lack of localization of solutions. External interventions may serve for a short-term, but long-term solutions need to be established by and for the beneficiaries and build upon existing local capacity. In this sense, what I call a sustainability and food security assessment (SFSA) can be completed as a first step to examine the environmental, economic and social sustainability viability of developing sustainable food systems, as shown in Figure 1. 


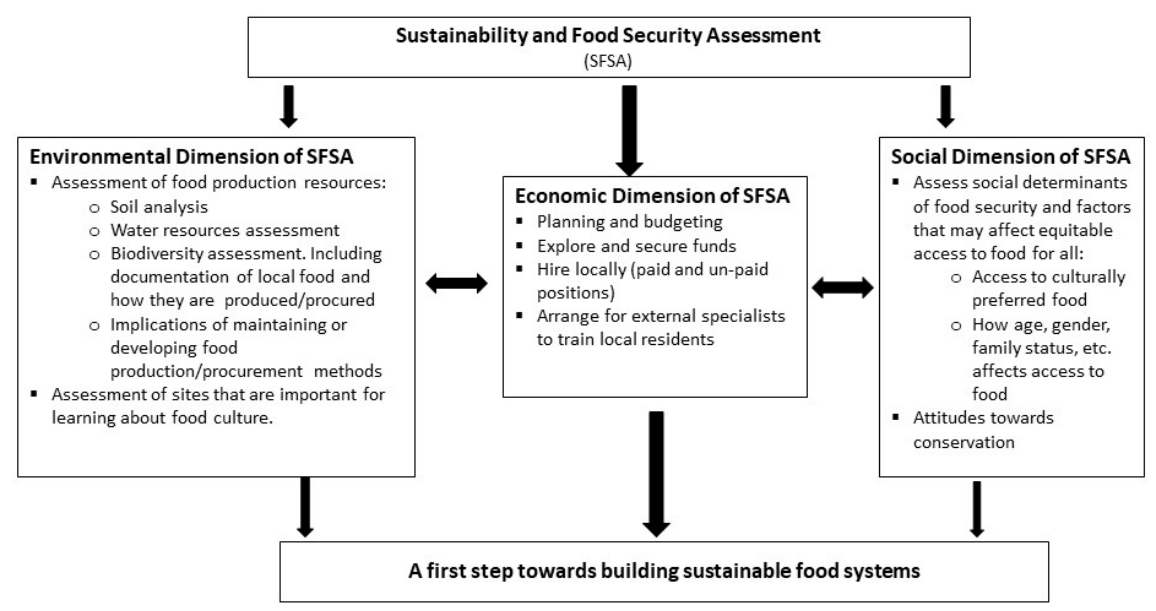

Figure 1. Sustainability and food security assessment framework

The environmental dimension of SFSA will involve assessing local food production resources available for developing sustainable food systems. Including soil quality and water capacity assessments, and environmental impact assessment for maintaining or developing new food production or procurement methods. This assessment will also involve documenting the various foods that are locally available and utilized for various uses, which may be sourced through production and wild food harvesting.

An environmental assessment will involve financial obligations, thus, an economic dimension of SFSA needs to be completed. This will involve planning, budgeting and exploring funding options. At this stage, it is important that efforts are made to first hire locally and explore those services that can be rendered by community members on a paid position and voluntary non-pay basis. Hiring locally will support community members, allow them work on something that is meaningful to their community, strengthen the sense of ownership of the project, and potentially save on cost. When hiring externally, efforts should be made for local people to be mentored by experts in various sustainability and food security fields. This will ensure the availability of local people to manage projects.

Food systems project done solely on the environmental and economic dimensions of SFSA is more likely to be less effective on the long term, this is why the social dimension of SFSA is necessary. The social dimension of SFSA deals with a fundamental aspect of sustainability and food security - people. Humans are at the centre of SFSA because of the importance of sustainable food systems for meeting food, livelihood, cultural, medicinal, spiritual, knowledge and recreational needs. And, because of the impact that humans are capable of exerting on the food system in the process of producing or sourcing food. Access to culturally acceptable food is an important determinant of food security for many and for the maintenance of health and wellbeing. Similarly, a people's culture and beliefs may influence how they interact with the environment and food system, including conservation practices during food production and procurement, and food waste reduction. Such strengths, and any weaknesses should be assessed in relation to how they may impact on the development of 
sustainable food systems. Furthermore, there may be sites of cultural, historical or spiritual importance to communities. There also may be important sites or seasons where learning about a community's food system and food culture happens or where knowledge exchange happens among community members. These areas should be assessed and put into consideration when developing sustainable food systems to protect their integrity and benefits for users. The social dimension of SFSA should also address the issue of equity as it relates to access to food for all. Factors such as gender, age, religion, race, family status and other social factors that may impact on equitable access to food for individuals in a community should be assessed and put into consideration.

\section{Conclusion}

Globally, the number of people facing food and nutritional security is growing alongside environmental degradation. To develop food production, humans have contributed in degrading the environment, thus, risking future food security prospects. Sustainability and food security problems are interrelated and should be addressed together. Sustainability and food insecurity are complex problems that need multi-dimensional solutions. Collaboration among multiple stakeholders can provide insight and transdisciplinary knowledge for solving such complex problems. Stakeholders can utilize the SFSA framework as a first of many steps towards building sustainable food systems at the community level. This can be built upon and applied according to specific context.

\section{Acknowledgement}

I would like to thank the reviewers and editor for providing valuable suggestions to improve this paper.

\section{References}

Abedi, M. (2017). 34\% of Canadian adults will be obese by 2025, and it will cost billions: report. Global News. Retrieved from https://globalnews.ca/news/3794111/canadaobesity-illness-costs/

AFN. (2007). Traditional Food, Are they Safe for First Nations Consumption? Retrieved from https://www.afn.ca/uploads/files/rp-traditional_foods_safety_paper_final.pdf

Ahmed, M. (2010). Economic dimensions of sustainable development, the fight against poverty and educational responses. International Review of Education / Internationale Zeitschrift Für Erziehungswissenschaft / Revue Internationale De L'Education, 56(2/3), 235-253. https://doi.org/10.1007/s11159-010-9166-8

Bacon, C. M., Getz, C., Kraus, S., Montenegro, M., \& Holland, K. (2012). The social dimensions of sustainability and change in diversified farming systems. Ecology and Society, 17(4), 41. https://doi.org/10.5751/ES-05226-170441

Berry, E. M., Dernini, S., Burlingame, B., Meybeck, A., \& Conforti, P. (2014). Food security and sustainability: can one exist without the other? Public Health Nutrition, 18(13), 1-10. https://doi.org/10.1017/S136898001500021X 
Castleden, H., Garvin, T., \& Huu-ay-ah First Nations (2008). Modifying Photovoice for Community Based Participatory Indigenous Research. Soc Sci Med, 66(6), 1393-405. https://doi.org/10.1016/j.socscimed.2007.11.030

Daly, H. E. (1999). Towards some Operational Principles of Sustainable Development. Ecological Economics, 1-6. Retrieved from https://ac.els-cdn.com/092180099090010R/1-s2.0-092180099090010R-main.pdf?_tid=08f34 400-6133-4eb6-966c-aa650fa6713f\&acdnat=1547266906_3aa4ead08bec8e1e4952ec3c8a4d1 $0 \mathrm{eb}$

FAO. (1996). An Introduction to the Basic Concepts of Food Security.

FAO. (2003). Trade Reforms and Food Security. Conceptualizing Linkages. Retrieved from http://www.fao.org/3/a-y4671e.pdf

FAO. (2003). Food Security. FAO Policy Brief, Issue 2. Retrieved from http://www.fao.org/fileadmin/templates/faoitaly/documents/pdf/pdf_Food_Security_Cocept_ Note.pdf

FAO, IFAD, UNICEF, WFP \& WHO (2019). The State of Food Security and Nutrition in the World 2019. Safeguarding against economic slowdowns and downturns. Rome, FAO.

GFN. (2019). World Footprint. Retrieved from https://www.footprintnetwork.org/ourwork/ecological-footprint/

High Level Task Force for Global Food and Nutrition Security. (2015). Compendium- Final Report, Zero Hunger Challenge Working Group. Retrieved from http:/www.un.org/en/issues/ food/taskforce/pdf/All\%20food\%20systems\%20are\%20sustainable.pdf

Huffpost. (2017). Obesity-Related Diseases Expected to Cost Australia \$21 Billion. Retrieved from https://www.huffingtonpost.com.au/2017/10/10/obesity-related-diseases-expected-tocost-australia-21-billion_a_23238534/

Huitt, W. (2007). Maslow's hierarchy of needs. Educational Psychology Interactive. Valdosta, GA: Valdosta State University. Retrieved from, http:/www.edpsycinteractive.org/topics/ regsys/maslow.html

IAP. (2018). Global food systems are failing humanity and speeding up climate change. Retrieved from https://www.interacademies.org/48945/Global-food-systems-are-failinghumanity-and-speeding-up-climate-change

Kanene, K. M. (2016). Indigenous practices of environmental sustainability in the Tonga community of southern Zambia. Jamba (Potchefstroom, South Africa), 8(1), 331. https://doi.org/10.4102/jamba.v8i1.331

Kidd, K. A., Blanchfield, P. J., Mills, K. H., Palace, V. P., Evans, R. E., Lazorchak, J. M., \& Flick, R. W. (2007). Collapse of a fish population after exposure to a synthetic estrogen. Proceedings of the National Academy of Sciences, 104(21), 8897-8901. https://doi.org/ 10.1073/pnas.0609568104 


\section{Macrothink}

Knauf, M. (2014). Is the Sustainability Revolution Devouring Its Own Children? Understanding Sustainability as a Travelling Concept and the Role Played by Two German Discourses on Sustainability. Forests, 5(11), 2647-2657. https://doi.org/10.3390/f5112647

Kuhnlein, H. V., Smitasiri, S., Yesudas, S., Bhattacharjee, L., Dan, L., \& Ahmed, S. (2006) Documenting Traditional Food Systems of Indigenous Peoples: International Case Studies. Guidelines for Procedures.

Lal, R. (2004). Soil carbon Sequestration Impacts on Global Climate Change and Food Security. Science, 304, 1623. https://doi.org/10.1126/science.1097396

Martens, T., Cidro, J., Hart, M. A., \& McLachlan, S. (2016) Understanding Indigenous Food Sovereignty through an Indigenous Research Paradigm. Journal of Indigenous Social Development, 5(1), 18-37.

Napoli, M. (2011). Towards a Food Security Multidimensional Index. Roma Tre, Universita Degli Studi. Retrieved from https://pdfs.semanticscholar.org/e37d/ad6f2c3e6d3f159ab68e6c 7867b3ea3034ad.pdf

Palmer, L. (2003). Discourses on Sustainability: A Foucauldian Approach. The Regional Institute Online Publishing. Retrieved from http://www.regional.org.au/au/apen/ 2003/refereed/020palmerl.htm

Power, E. (2008). Conceptualizing food security for Aboriginal people in Canada. Can J Public Health, 99(2), 95-97. https://doi.org/10.1007/BF03405452

Purvis, B., Mao, Y., \& Robinson, D. (2018). Three pillars of sustainability: in search of conceptual origins. Sustain Sci, 1-15.

Rankoana, S. A. (2016). Sustainable Use and Management of Indigenous Plant Resources: A Case of Mantheding Community in Limpopo Province, South Africa. Sustainability, 8, 221. https://doi.org/10.3390/su8030221

Riedel, A. (2015). Sustainability as an Ethical Principle: Ensuring Its Systematic Place in Professional Nursing Practice. Healthcare (Basel, Switzerland), 4(1), 2. https://doi.org/ 10.3390/healthcare4010002

Robinson, J. (2004). Squaring the Circle? Some Thoughts about Sustainable Development. Ecological Economics, 48, 369-384. https://doi.org/10.1016/j.ecolecon.2003.10.017

Roe, L. (2019). Biodiversity Loss - More than an Environmental Emergency. The Lancet, 3(7), PE287-PE289. https://doi.org/10.1016/S2542-5196(19)30113-5

Simon, G-A. (2012). Food Security: Definition; Four Dimensions and History. University of Roma Tre.

Sobreliva, C. (2008). The Role of Indigenous Peoples in Biodiversity Conservation. The natural but often forgotten partners. The International bank for Restructuring and Development/World Bank. Washington, D.C., U.S.A. Retrieved from https://siteresources. worldbank.org/INTBIODIVERSITY/Resources/RoleofIndigenousPeoplesinBiodiversityCons 
ervation.pdf

Swaminathan, M. S., \& Jana, S. (1992). Biodiversity implications of Global Food Security. Macmillan, India.

Tscharntkea, T., Clougha, Y., Wangerb, T. C., Jackson, L., Motzkea, Perfectoe, I., Vandermeerf, J., \& Whitbreadg, A. (2011). Global food security, biodiversity conservation and the future of agricultural intensification. Biological Conservation, 151(2012), 53-59.

UNEP. (2016). Rate of Environmental Damage Increasing Across Planet but Still Time to Reverse Worst Impact. Retrieved from https://www.un.org/sustainabledevelopment/ blog/2016/05/rate-of-environmental-damage-increasing-across-planet-but-still-time-to-revers e-worst-impacts/

UNRISD. (2018). Social Dimensions of Sustainable Development. Retrieved from http://www.unrisd.org/unrisd/website/projects.nsf/(httpProgrammeAreas)/E6ED96D4F732C DBB8025790C005CE947?OpenDocument

Vallance, S., Perkins, H. C., \& Dixon, J. E. (2011). What is Social Sustainability? A Clarification of Concepts. Geoforum, 42, 342-488. https://doi.org/10.1016/j.geoforum.2011. 01.002

Whitmee, S. (2015). safeguarding Human Health in the Anthropocene Epoch: Report of the Rockefeller Foundation-Lancet Commission on planetary Health. The Lancet, 386, 1973-2028. https://doi.org/10.1016/S0140-6736(15)60901-1

Wiersum, K. F. (1995). 200 Years of Sustainability in Forestry: Lessons from History. Environmental Management, 19(3), 321-329. https://doi.org/10.1007/BF02471975

World Commission on Environment and Development [WCED]. (1987). Our Common Future. Retrieved from http://mom.gov.af/Content/files/Bruntland_Report.pdf

\section{Note}

Note 1. Green Revolution is associated with the era of notable increase in mostly grain production in the mid- $20^{\text {th }}$ century due to research and technology which resulted in high yield variety of such crops accompanied by intensive use of chemical fertilizer and pesticides

\section{Copyright Disclaimer}

Copyright for this article is retained by the author(s), with first publication rights granted to the journal.

This is an open-access article distributed under the terms and conditions of the Creative Commons Attribution license (http://creativecommons.org/licenses/by/3.0/). 